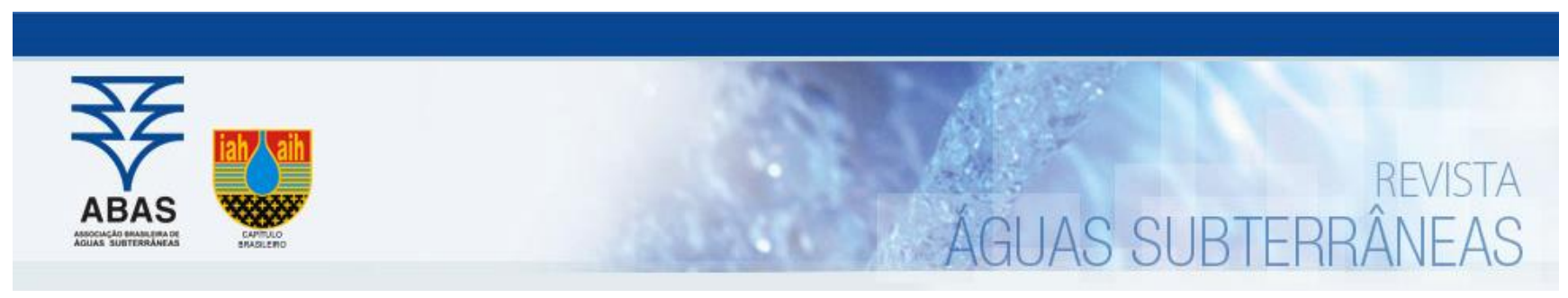

Artigos

\title{
Método de Valoração da Água Subterrânea Impactada por Atividades Contaminantes no Estado de São Paulo
}

\section{Method for economic valuation of groundwaters impacted by contaminant activities in the state of São Paulo}

\author{
Reginaldo Antonio Bertolo1; Ricardo Hirata1; Osvaldo Aly Junior ${ }^{1 凶}$ \\ 1 Centro de Pesquisas de Águas Subterrâneas. Instituto de Geociências da Universidade de São Paulo (CEPAS|USP), São \\ Paulo, SP.
}

\section{bertolo@usp.br, rhirata@usp.br, oalyjunior@gmail.com}

\section{Palavras-chave:}

Valoração.

Dano Ambiental.

Áreas Contaminadas.

Água Subterrânea.

Aquífero.

Reparação Integral.

Recuperação Ambiental.

\section{Resumo}

As águas subterrâneas apresentam uma notável importância para os ecossistemas, atuando na perenidade de rios e na sustentação da vida aquática, assim como no atendimento de vários tipos de necessidades humanas. Estas águas vêm sendo deterioradas nas últimas décadas, em especial nas áreas urbanas, colocando em risco suas funç̃es e serviços ecossistêmicos. No Estado de São Paulo, a aplicação dos procedimentos de gerenciamento de áreas contaminadas (GAC), previstos na Lei Estadual 13577/2009 e demais instrumentos, contribuem para a melhoria das condições ambientais e propiciam condições seguras de uso do solo. Por outro lado, reconhece-se que as ações previstas no GAC não resultam na extração total de contaminantes do meio contaminado, em especial nas águas subterrâneas, o que propicia a criação de não conformidades com leis federais mais amplas, que exigem do responsável a reparação integral de um dano ambiental. Este trabalho objetiva apresentar um método de valoração dos serviços ecossistêmicos prestados pelas águas subterrâneas e aquíferos, servindo como parâmetro para a quantificação da reparação integral do dano ambiental. 0 método implica na realização do cálculo dos volumes de água subterrânea associados ao problema ambiental, multiplicados por um valor de custo unitário da água subterrânea. As equações utilizadas para a quantificação dos volumes de água são apresentadas, assim como uma discussão sobre a utilização dos valores unitários. O resultado final deste trabalho, avalia-se, é a criação de conformidades entre as legislações Estadual e Federal que tratam do tema.

Abstract

Keywords:

Valuation.

Environmental Damage.

Contaminated Sites.

Groundwater.

Aquifer.

Full Compensation.

Environmental Recovery.

Revisado por pares.

Recebido em: 26/01/2019.

Aprovado em: 08/08/2019.

Groundwater has a remarkable importance for ecosystems, ensuring river flows and sustaining aquatic life, as well as on meeting various types of human needs. These waters have been deteriorating in the last decades, especially in urban areas, putting at risk their ecosystem functions and services. The procedures for the management of contaminated sites (GAC) in the state of São Paulo, described in the state Law 13577/2009 and its instruments, contribute to the improvement of environmental conditions and create safe conditions for land use. However, it is acknowledged that the actions foreseen in the GAC procedures do not result in the total extraction of contaminants from the environment, especially in groundwater, which leads to the creation of non-compliance with broader federal laws, which require full compensation of the environmental damages. This work aims to present a method for calculating the economic value of ecosystem services provided by groundwater and aquifers, serving as a parameter for the quantification of the full compensation of the environmental damage. The method implies the accomplishment of the calculation of groundwater volumes associated with the environmental problem, multiplied by a unit cost value of groundwater. The equations used to quantify water volumes are presented, as well as a discussion on the use of the unit values. The final result of this work, it is believed, is the creation of conformities between the State and Federal legislations that deal with the subject.

DOI: http:/dx.doi.org/10.14295/ras.v33i3.29479

\section{INTRODUÇÃO}

As águas subterrâneas apresentam significativa relevância no abastecimento público no Brasil, participando do suprimento de $75 \%$ dos núcleos urbanos paulistas e de 53\% nos municípios brasileiros (ANA, 2015). Embora os aquíferos não sejam a principal fonte de água na Região Metropolitana de São Paulo (RMSP), os poços tubulares privados são essenciais por equilibrar as demandas: a somatória das extrações de mais de 12 mil poços privados faz dos aquíferos um dos principais mananciais disponíveis, com extrações superiores a 10 mil litros por segundo (HIRATA et al., 2012).

A despeito da importância que a água subterrânea apresenta na maioria das situações, tem-se notado que os aquíferos vêm sofrendo deterioração progressiva ao longo das décadas, provocada pelas diferentes atividades humanas que ocorrem em 
áreas urbanas e rurais. Dentre elas, as áreas contaminadas apresentam destaque, por serem geradas comumente em ambiente urbano-industrial onde há intensa utilização de água subterrânea por poços de abastecimento privados.

O Estado de São Paulo reporta a existência de 6110 áreas contaminadas (CETESB, 2018), sendo a maioria dessas (4384 casos) associadas com vazamentos de combustíveis em postos de serviços. Os casos conhecidos em indústrias (1158) perfazem uma minoria no cadastro, a despeito do elevado potencial de existência de casos ainda desconhecidos, dada a existência de milhares de estabelecimentos de potencial poluidor (com destaque para a cadeia produtiva de veículos automotores e da indústria química - CNI, 2014), e a existência de ao menos 2000 áreas industriais desativadas com elevado potencial poluidor (CUNHA, 1997).

Nas últimas décadas, a legislação e as políticas públicas têm sido aprimoradas, resultando na melhora das ações de gerenciamento das áreas contaminadas. Entretanto, falta à sociedade civil e aos tomadores de decisão a realização de ações efetivas para o aperfeiçoamento da proteção do recurso hídrico subterrâneo. Avalia-se que tal situação seja consequência do desconhecimento pela sociedade do real papel e valor das águas subterrâneas, não somente para o abastecimento público e privado, mas também de suas funções e serviços ecossistêmicos.

A crise hídrica paulista de 2014 e 2015 fez reforçar a importância do papel das águas subterrâneas na RMSP (BERTOLO et al., 2015). Houve uma corrida desenfreada pela construção de poços durante a estiagem, especialmente de forma irregular. Até mesmo a principal concessionária de abastecimento público (SABESP), que considera apenas os reservatórios de águas superficiais como relevantes para o abastecimento, rendeu-se à possibilidade de construção de poços tubulares em áreas de maior estresse hídrico (CEPAS-USP, 2016).

Ainda durante a referida crise, notou-se, entretanto, que os aquíferos da região industrial do Jurubatuba encontravam-se cheios, mas impedidos de ser utilizados devido à ocorrência de contaminação por solventes organoclorados. Nesta região, 41 poços de abastecimento foram interditados pelo Poder Público em 2005, representando prejuízos da ordem de dezenas de milhões de reais, que seriam evitados caso a água subterrânea pudesse de alguma forma ser utilizada.

A RMSP apresenta 136 áreas com potencial de contaminação igual ou superior ao encontrado em Jurubatuba (FABHAT-SERVMAR, 2012), ou seja, há outras inúmeras áreas industrializadas com elevado potencial de contaminação de aquíferos, com pouco ou nenhum controle de qualidade da água subterrânea explotada. Se por um lado, a água subterrânea contribui para a segurança hídrica na RMSP, por outro nota-se que a sociedade sofre um significativo prejuízo com a perda deste recurso quando a poluição ocorre. E esta é a principal justificativa para se estabelecer uma metodologia para definir um valor monetário da importância da água subterrânea para a sociedade.

Este trabalho objetiva descrever um método para o cálculo do valor econômico dos serviços ecossistêmicos prestados pelas águas subterrâneas e aquíferos. Este método possibilita realizar o cálculo de indenização à sociedade pelo período em que ela se mantém privada do uso do recurso contaminado, servindo como parâmetro para a quantificação da reparação integral do dano ambiental.

Os exemplos mais comuns de valoração de recursos ambientais ameaçados por atividades humanas estão relacionadas com biodiversidade, florestas e corpos de água superficial, como as apresentadas em Motta (1997). Sobre as águas subterrâneas, estudos sobre danos econômicos existem especialmente para aspectos quantitativos do recurso (ex. BANN; WOOD, 2012; FENICHEL et al., 2016; NRC, 1997) e para casos de alteração de qualidade em ambiente rural ou por intrusão salina (ex. WALKER; HOEHN, 1990; RINAUDO et al., 2003; NRC, 1997). Estudos sobre danos econômicos originados pela existência de áreas contaminadas referem-se especialmente sobre estigma e perda de valor de propriedades (ex. PAGE; RABINOWITZ, 2007; IPT, 2018). Metodologias de valoração similares à descrita neste artigo, que apresenta a água subterrânea como um recurso submetido a riscos pela ocorrência de áreas contaminadas, são raras na literatura científica, mas são discutidas em NRC (1997), para o caso de contaminação de aquíferos por organoclorados de Woburn (EUA), e em Dunford (2000).

A aplicação da metodologia de valoração de águas subterrâneas pelo Poder Público, de forma pioneira, pode representar um avanço significativo para a proteção do recurso hídrico e da saúde pública, dado que fundos são necessários para a execução de projetos de monitoramento e de avaliação hidrogeológica em áreas urbanas dependentes de mananciais subterrâneos e afetadas por áreas contaminadas (Bertolo, 2017).

\section{FUNÇÕES, SERVIÇOS E A VALORAÇÃO ECONÔMICA AMBI- ENTAL DA ÁGUA SUBTERRÂNEA}

Funções ecossistêmicas são definidas como as interações existentes entre os elementos estruturais de um ecossistema, incluindo a transferência de energia, a ciclagem de nutrientes, a regulação climática e o ciclo da água (DALY; FARLEY, 2008). Os serviços ecossistêmicos são aqueles prestados pelos ecossistemas e espécies para a sustentação das condições da vida humana na Terra, ou seja, os ecossistemas geram benefícios diretos e indiretos ao ser humano (DALY, 1997).

No que se refere às águas subterrâneas, Rebouças (2006) e Danielopol et al. (2004) identificam as suas principais funções ecossistêmicas como de Habitat, Regulação, Informação e Produção. Já os principais serviços ecossistêmicos prestados pelas águas subterrâneas são identificados como de Provisão, Regulação, Suporte e Cultural. Esses conceitos foram detalhados em Aly Jr et al. (2015) e servem de base para a metodologia de valoração.

A valoração ambiental é um método através do qual se busca estimar os custos dos passivos ambientais sobre o patrimônio natural (ANDRADE, 2010; DUNFORD, 2000; JOB, 2010). A valoração é o resultado do emprego de um conjunto de ferramentas de suporte à gestão ambiental e que permite estimar 
de forma preventiva e/ou corretiva o valor dos serviços prestados pela natureza para a sociedade (MOTA, 1997, 2006).

O cálculo econômico dos recursos ambientais é realizado através do método da Valoração Econômica do Recurso Ambiental (VERA - Equação 1) (MOTA, 1997, 2006):

VERA = Valor de Uso Direto + Valor de Uso Indireto + Valor de Opção + Valor de Existência

No caso das águas subterrâneas e aquíferos, a composição do VERA dá-se como (HARDISTY; ÖZDEMIROGLU, 2005):

Valor de uso direto: está relacionado com a apropriação das águas subterrâneas via extração, como o fornecimento de água potável ou não potável para os diversos fins;

Valor de uso indireto: se relaciona com benefícios associados com as funções ecossistêmicas, ou seja, com a dinâmica e o funcionamento dos aquíferos, como o fluxo de base dos rios e a atenuação natural dos contaminantes nos aquíferos;

Valor de opção: é o valor atribuído à preservação do recurso que pode estar ameaçado para uso direto e/ou indireto no futuro; e

Valor de existência: são intrínsecos dos recursos e estão dissociados do uso. O valor é oriundo de uma posição moral, cultural, ética ou altruísta em relação à existência do recurso, mesmo que não representem uso atual ou futuro. Este valor é de definição subjetiva, é determinado por intermédio de entrevistas com a população e é normalmente considerado na equação quando os valores de uso direto, indireto e de opção não são aplicáveis.

\section{REPARAÇÃO INTEGRAL VERSUS RECUPERAÇÃO DE ÁREAS CONTAMINADAS}

De acordo com a Constituição Federal (artigo 225, §3º e a Lei 6938/81 da Política Nacional de Meio Ambiente (artigo 14, $\S 1^{\circ}$ ), o Brasil escolheu adotar a ideia de que todo dano ambiental deverá ser integralmente reparado pelo poluidor até a restituição completa do equilíbrio ecológico e das funções e serviços do ecossistema impactado. A consequência prática deste conjunto de regras é que, em casos de contaminação de água subterrânea, os serviços de remediação deveriam ocorrer até que ao menos os limites de potabilidade dos poluentes (Anexo XX da Portaria de Consolidação 5/2017-MS) sejam atingidos. Encontra-se incluída nestas regras, a ideia de que o poluidor deverá ressarcir a sociedade de todo o prejuízo que a poluição causou no período entre o início do dano até a sua reparação total, período este que a sociedade permaneceu impedida de se beneficiar dos serviços prestados pelo recurso.

O processo de Gerenciamento de Áreas Contaminadas (GAC) apresenta, como ferramentas importantes, as regras descritas na Resolução CONAMA 420/2009 e na Lei 13577/2009 (para o Estado de São Paulo). Esta Legislação apresenta a recuperação ambiental como a meta a ser alcançada, definindoa como um conjunto de ações que visam a isolar, conter, minimizar ou eliminar a contaminação, objetivando a utilização da área contaminada para determinado uso.

O GAC parte do princípio de que a recuperação da aptidão para determinado uso do solo é mais viável técnica e economicamente do que a reparação integral das funções e serviços ecossistêmicos originais. Portanto, o GAC não tem como meta a reparação integral do dano, mas a garantia do uso seguro da área contaminada para uma finalidade declarada. Nos casos de áreas urbanas, o GAC consiste na adoção de várias medidas que visam a preservar a saúde humana na área recuperada, mas admite a presença de alguma quantidade remanescente do contaminante em concentrações seguras para o uso futuro que se declara fazer da área.

No processo de GAC, as dimensões e intensidades da contaminação são mensuradas nos diferentes meios afetados, os receptores à contaminação são identificados e os riscos são quantificados. A recuperação da área contaminada é realizada através de ações de remediação e ações de compatibilização do uso do solo, denominadas de Plano de Intervenção. Na remediação, ações são realizadas visando à aceleração da redução das concentrações dos contaminantes até que sejam atingidas as Concentrações Máximas Aceitáveis (CMAs). Estas ações são somadas a outras medidas de controle institucional, que possibilitam a utilização de uma área contendo o contaminante em concentrações seguras para os seres humanos e para o meio ambiente, desde que certas precauções sejam tomadas.

Os campos de ação da remediação e da reparação integral são visualizados na Figura 1, que apresenta, de forma genérica, o comportamento das concentrações de um contaminante na água subterrânea desde o tempo inicial $(\mathrm{t}=0)$ até o tempo em que a concentração atingiu o limite seguro para a ingestão (potabilidade ou CMA para ingestão) $(t=4)$, passando por um período intermediário de execução de atividades de remediação, entre os tempos $t=1$ e $t=3$. 
Figura 1 - Comportamento genérico das concentrações de contaminantes na água subterrânea antes, durante e após a execução de medidas de remediação

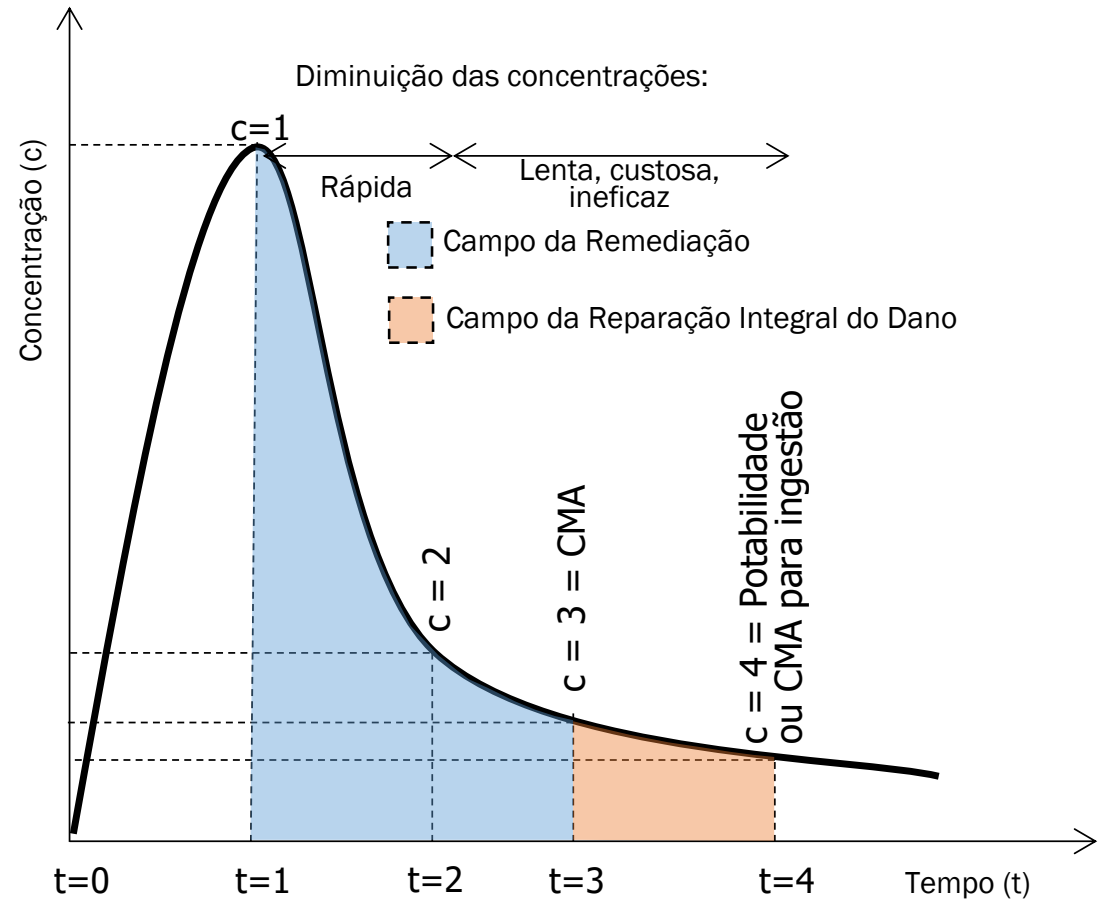

Durante o espalhamento da contaminação, as concentrações se elevam entre os tempos $t=0$ e $t=1$. Após a realização das investigações, avaliação de riscos à saúde humana/ecológica (se necessário), da definição de Concentrações Máximas Aceitáveis (CMAs) e do plano de intervenção no tempo $t=1$, a remediação se inicia e se estende até o tempo $t=3$, quando a CMA é atingida. As concentrações diminuem rapidamente de $\mathrm{t}=1$ a $\mathrm{t}=2$, mas o ritmo da queda das concentrações do contaminante na água subterrânea diminui consideravelmente de $\mathrm{t}=2$ a $\mathrm{t}=3$ (CMAs). Entre $\mathrm{t}=3$ e $\mathrm{t}=4$, o método de $\mathrm{GAC}$ garante que os riscos estão controlados, mas a água subterrânea está impossibilitada de uso como fonte de água potável, enquanto os serviços ambientais de atenuação natural não reduzem as concentrações até os limites seguros para a ingestão (c=4). 0 tempo entre $t=3$ e $t=4$, não raro, é longo, pois as concentrações c=3 (CMAs) e c=4 (limite seguro para a ingestão) são pequenas. Isto, associado às complexidades hidrogeológicas, faz frequentemente criar limitações que tornam a remediação ineficaz e antieconômica. Desta forma, é razoável considerar a existência de situações de contaminação de água subterrânea classificáveis como economicamente e/ou tecnicamente inviáveis, dada a impossibilidade das concentrações alcançarem os limites seguros para a ingestão entre os tempos $t=2$ e $\mathrm{t}=4$ num período razoável e compatível com o estabelecido pela legislação.

A complexidade hidrogeológica e a toxicidade dos contaminantes fazem com que as distâncias entre as concentrações $c=2, c=3$ e $c=4$ sejam específicas para cada caso. Complexidades hidrogeológicas e biogeoquímicas podem fazer a concentração $c=2$ ser muito maior que a $c=3$, inviabilizando qualquer ação de remediação; concentrações $c=3$ (CMA) podem ser menores que os limites de potabilidade $(c=4)$ em algumas situações, o que pode tornar questionável o próprio valor da potabilidade como indicador da reparação integral do dano ambiental.

Na maioria das situações, entretanto, as ações de recuperação (remediação) são mais limitadas que a reparação integral do dano, especialmente por razões econômicas e técnicas. As ações de GAC, apesar desta limitação, representam uma abordagem imprescindivel, pois possibilitam a reabilitação, revitalização e reutilização de áreas contaminadas de forma segura e viável economicamente. A realização da valoração da água subterrânea é, portanto, o caminho possível para complementar a lacuna que existe entre a recuperação da qualidade da água subterrânea executada pelas ações de GAC e a reparação integral do dano a este recurso exigidas pela Legislação. Os recursos obtidos com a aplicação da ferramenta de valoração poderiam ser revertidas para a execução de projetos destinados à própria melhoria das condições dos recursos hídricos subterrâneos e à proteção da saúde pública. A valoração não representa uma ferramenta de punição ao responsável legal pela área contaminada, mas um instrumento técnico que possibilita obter recursos que complementam os trabalhos de gestão de áreas contaminadas pelo poder público, proporcional ao tamanho do problema ambiental.

A valoração de águas subterrâneas pode ser realizada em paralelo aos procedimentos de GAC. Isto se deve pois dados do meio físico e da contaminação são necessários para a quantificação do volume de água que foi impactada. Estes estarão disponíveis com a conclusão da etapa de Investigação DetaIhada do GAC, quando as plumas terão seus limites e taxas de propagação definidos, assim como as CMAs e o Plano de Intervenção (ações de remediação e/ou de controle institucio- 
nal). 0 momento ideal para a execução da valoração corresponde, portanto, ao tempo t=1 (Figura 1).

\section{MÉTODO DE QUANTIFICAÇÃO DO VALOR DA ÁGUA SUBTER- RÂNEA}

\subsection{Equações de Valoração da Água Subterrânea}

0 quadro 1 exibe as equações gerais que são utilizadas para a valoração da água subterrânea (VERA) em suas diferentes funções e serviços ecossistêmicos (Equação 1). De uma forma geral, para as diferentes finalidades, a valoração é calculada multiplicando-se um volume de água num determinado tempo por um valor de custo unitário da água.

A Equação 2 é utilizada nas situações em que um volume de aquífero com água subterrânea contaminada é conhecido. 0 valor total da água corresponde à multiplicação deste volume por um custo unitário de sua substituição, que varia em função da finalidade da água, se para fins potáveis ou não potáveis.

A Equação 3 se aplica especialmente nas situações de uso indireto da água subterrânea, quando suas funções e serviços ecossistêmicos estão comprometidos pela inadequação de sua qualidade como fluxo de base para um corpo de água superficial. O valor da água se calcula multiplicando a vazão de descarga do aquífero pelo tempo em que o aquífero deixa de prestar sua função/serviço, por um custo unitário, que pode ser associado ao tratamento da água para adequação ao enquadramento da classe do corpo receptor.

A Equação 4 é aplicada nas situações em que se deseja calcular os serviços prestados pelo próprio aquífero em realizar a atenuação natural de uma pluma de contaminação. Sabendose as dimensões de uma pluma, calcula-se a vazão do aquífero que passa através da pluma durante o tempo em que os serviços de atenuação natural realizam a reparação integral do dano ambiental.

A Equação 5 pode ser aplicada em situações específicas, quando um dano ambiental resulta em perdas coletivas, como numa hipotética situação de contaminação de um aquífero de água mineral em um balneário. As perdas de faturamento da economia do balneário durante o tempo de recuperação da atividade econômica podem servir de critério para a determinação do valor total da água.

Para o cálculo do valor de opção, são utilizadas as mesmas equações para a obtenção do valor de uso direto. 0 valor de existência, como indicado anteriormente, é subjetivo e determinado nas situações em que os valores dos demais usos não são aplicáveis.

Quadro 1 - Equações gerais para dimensionar o valor da água subterrânea em suas diferentes funções e serviços

\begin{tabular}{|c|c|}
\hline Função e/ou Serviço Ecossistêmico & Equação \\
\hline $\begin{array}{l}\text { Serviço de Provisão: } \\
\text { Fornecimento de água potável ou não potável, me- } \\
\text { diante extração, para consumo humano e diversos } \\
\text { fins (uso direto). }\end{array}$ & \multirow[b]{2}{*}{$\begin{array}{c}\mathrm{VA}=\text { Valor da Água (em } \mathrm{R} \$) ; \\
\mathrm{V}_{\text {cont }}=\text { Volume de água contaminada em um aquífero }\left(\mathrm{em} \mathrm{m}^{3}\right) \\
\mathrm{R} \$=\text { Custo de substituição da água }\left(\mathrm{em} \mathrm{R} \$ / \mathrm{m}^{3}\right)\end{array}$} \\
\hline $\begin{array}{l}\text { Função de Regulação/ } \\
\text { Serviços de Suporte: Reservação subterrânea de } \\
\text { água de recarga por chuva ou por recarga artificial } \\
\text { (uso indireto). }\end{array}$ & \\
\hline $\begin{array}{l}\text { Função de Habitat/ Serviços de Regulação: Fluxo } \\
\text { de base que pereniza rios, garante irrigação, } \\
\text { pesca, aquicultura, transporte fluvial e geração de } \\
\text { energia } \\
\text { (uso indireto). }\end{array}$ & \multirow{3}{*}{ 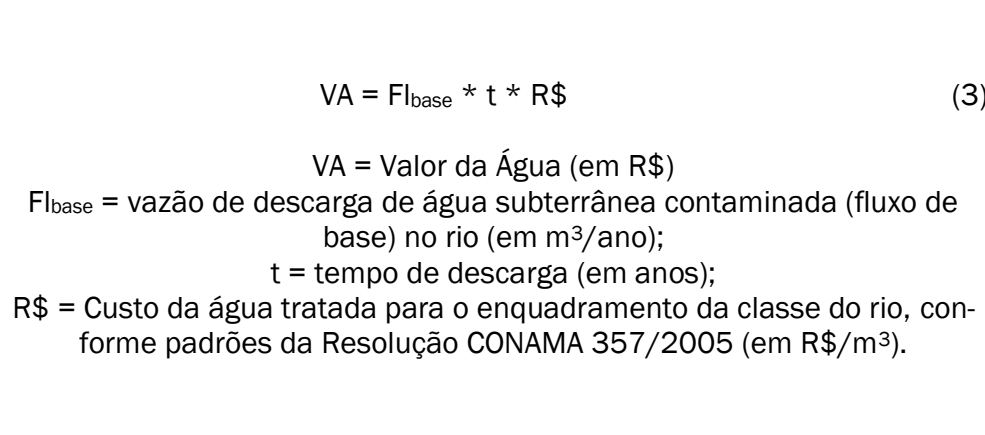 } \\
\hline $\begin{array}{c}\text { Serviço de Suporte: } \\
\text { Fluxo de base dilui esgotos } \\
\text { (uso indireto). }\end{array}$ & \\
\hline $\begin{array}{c}\text { Função de Produção: } \\
\text { Fluxo de base provê suporte para a biodiversidade } \\
\text { (uso indireto). }\end{array}$ & \\
\hline & $V A=Q_{\text {aqf }} * t * R \$$ \\
\hline $\begin{array}{l}\text { Serviço de Suporte: } \\
\text { Atenuação natural dos contaminantes } \\
\text { (uso indireto). }\end{array}$ & 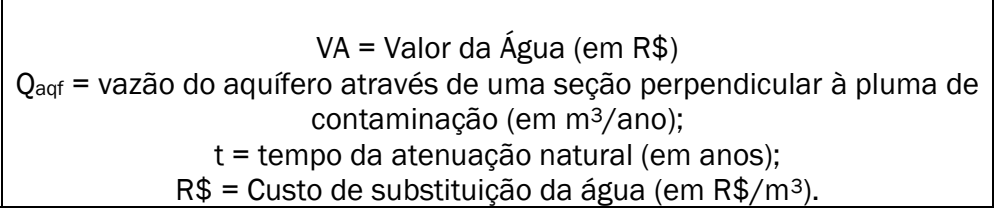 \\
\hline $\begin{array}{c}\text { Função de Informação/ Serviços Culturais: } \\
\text { Turismo e lazer. }\end{array}$ & $\begin{array}{l}\text { VA = Perda faturamento (R\$/ano) x Tempo de Recuperação da Atividade } \\
\text { Econômica (anos) }\end{array}$ \\
\hline
\end{tabular}




\subsection{Cálculos de Volumes de Água Subterrânea a serem Valo- rados}

Considerando a existência de uma pluma de contaminação em um aquífero (Figura 2) e o comportamento das concentrações no tempo conforme indicado na Figura 1, os volumes de água a serem valorados correspondem à somatória: (1) do volume da pluma no tempo $t=1$; (2) do volume de água relativo ao tempo decorrido entre os momentos $t=3$ e $t=4$ (associado com os serviços ambientais prestados pela atenuação natural no futuro, após a remediação); e (3) do volume de aquífero adjacente à pluma de contaminação, cuja opção de uso da água é impedida para evitar a migração da pluma induzida pelo bombeamento de um poço.

As figuras 2 e 3 conceituam os volumes da pluma e da área adjacente de restrição de uso futuro no tempo t=1. A Equação
1, de valoração econômica (VERA), é utilizada para calcular os volumes de água considerados, mediante um custo unitário de água potável ou não potável. A Equação 6 representa a VERA adaptada a esta situação.

VERA $=[$ Volume de Uso Direto + Volume de Uso Indireto + Volume de Opção] * $R \$$

Onde:

Volume de Uso Direto $=$ Volume da pluma no presente $\left(\mathrm{t}_{1}\right)(\mathrm{Fi}-$ gura 2 e Equação 1):

Volume de Uso Indireto = Volume da pluma previsto entre t $_{3} \mathrm{e}$ $\mathrm{t}_{4}$ (Equação 4);

Volume de Opção = Volume de água potável adjacente à pluma, com restrição de uso futuro (Figuras 2 e 3 e Equação 1);

$\mathrm{R} \$$ = valor do $\mathrm{m}^{3}$ de água potável

Figura 2 - Situação em planta de uma pluma de contaminação genérica no tempo t=1, incluindo a área adjacente, de restrição de uso futuro. As distâncias $\mathrm{R}$ dos poços de produção $\mathrm{P}$ em relação à pluma de contaminação definem a área de restrição de bombeamento (em verde claro)

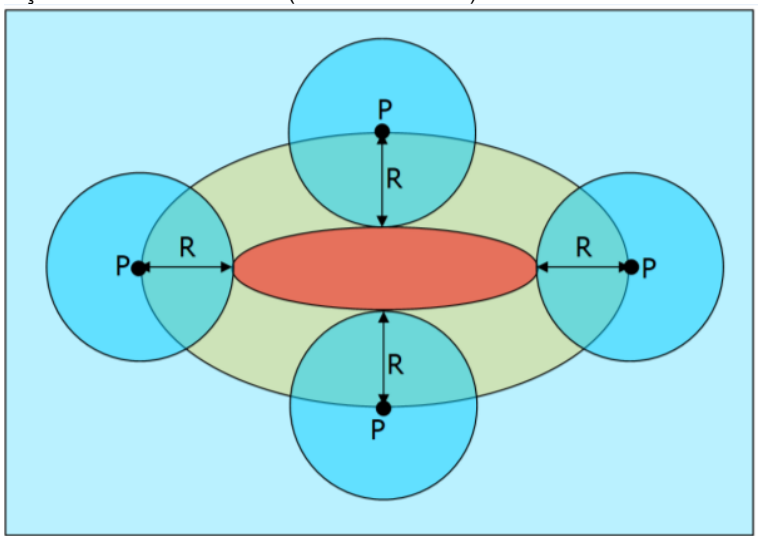

1. Pluma de contaminação no tempo $t_{1}$

2. Área adjacente à pluma com água subterrânea potável, mas com restrição de uso futuro, por existência de risco de migração da pluma caso haja bombeamento.

3. Área segura, sem restrição de uso futuro da água potável.

\subsubsection{Cálculo do volume de uso direto (pluma no tempo $t=1$ )}

O volume de água subterrânea na pluma de contaminação no tempo t=1 é obtido pela medição da área da pluma, da sua espessura e da porosidade total do aquífero na pluma, com a utilização da Equação 7. Os limites da pluma correspondem a todo o volume com concentrações acima dos limites de potabilidade do contaminante.

$$
\mathrm{V}_{\text {pluma }}\left(\mathrm{t}_{1}\right)=\mathrm{V}_{\text {aqcont }} * \mathrm{n}
$$

onde:

$V_{\text {aqcont }}=$ volume de aquífero contaminado (acima da potabilidade). Representa a área da pluma vezes a sua espessura média ( $\left.\mathrm{L}^{3}\right)$; $\mathrm{n}=$ porosidade total do aquífero $\left(\mathrm{L}^{3} \cdot \mathrm{L}^{-3}\right)$.

\subsubsection{Cálculo do volume de uso indireto (pluma entre os tem- pos $t=3$ e $t=4$ )}

Como indicado anteriormente, uma pluma de contaminação residual poderá ocorrer entre os tempos do fim das atividades de remediação ( $t=3$, quando as CMAs são alcançadas) e o atingimento da potabilidade da água subterrânea ( $t=4$, Figura 1). Neste período, os serviços ambientais de atenuação natural serão prestados pelo aquífero, mas a água subterrânea ainda terá a sua utilização restringida.

O Volume t3-t4 (Equação 8) é obtido multiplicando-se a vazão do trecho do aquífero impactado (Lei de Darcy - Equação 9) pelo tempo necessário para o decaimento das concentrações $\mathrm{C}_{3}$ a $\mathrm{C}_{4}$ por atenuação natural (Figura 1). Este tempo se calcula através da equação de decaimento de primeira ordem (Equação 10).

$$
\begin{gathered}
\text { Volume } \mathrm{t}_{3}-\mathrm{t}_{4}=\mathrm{Q} * \mathrm{t} \\
\mathrm{Q}=\mathrm{K}^{*} \mathrm{~A}^{*} \Delta \mathrm{h} / \Delta \mathrm{l} \\
\mathrm{t}=-\ln \left(\mathrm{C}_{4} / \mathrm{C}_{3}\right) / \lambda
\end{gathered}
$$

onde:

$\mathrm{Q}=$ vazão do aquífero impactado $\left(\mathrm{L}^{3} \cdot \mathrm{T}^{-1}\right)$;

$\mathrm{t}=$ tempo do decaimento das concentrações entre $\mathrm{t}=3 \mathrm{e} \mathrm{t}=4$ $(\mathrm{T})$;

$\mathrm{K}=$ condutividade hidráulica $(\mathrm{L} / \mathrm{T})$; 
A = área da seção transversal à pluma de contaminação, perpendicular ao sentido do fluxo de água subterrânea ( $\mathrm{L}^{2}$ );

$\Delta \mathrm{h} / \Delta \mathrm{l}=$ gradiente hidráulico $\left(\mathrm{L} . \mathrm{L}^{-1}\right)$;

$\mathrm{C}_{3}=$ concentração da meta de remediação baseada em risco

(M.L-3);

$\mathrm{C}_{4}=$ concentração da meta de potabilidade ou CMA de inges-

tão (M.L-3);

$\lambda=$ taxa constante de decaimento $\left(\mathrm{T}^{-1}\right)$.
A taxa constante de decaimento pode ser obtida por três métodos descritos em Wiedemeier et al., (1999): pelo balanço de massa, através de monitoramento das concentrações no campo por no mínimo três eventos anuais; pelo uso de traçadores, como o trimetilbenzeno, seguida de aplicação de equação apropriada; e o método que assume equilíbrio de estado estacionário, desenvolvida por Buscheck e Alcantar (1995).

Figura 3 - Seção exibindo o modelo conceitual de uma pluma de contaminação no tempo t=1 (em amarelo), num aquífero contendo um poço, incluindo a área adjacente, de restrição de uso futuro, delimitada pelas distâncias de segurança ao redor da pluma e pela região imediatamente abaixo da pluma, até a base útil explotável do aquífero

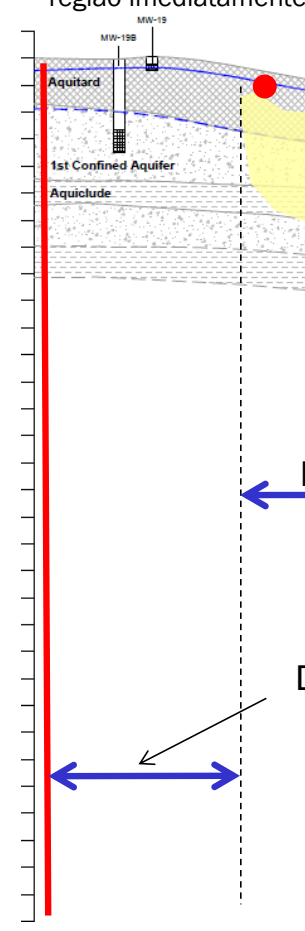

Distâncias de segurança ao redor da pluma

\subsubsection{Cálculo do volume de opção}

0 volume de opção corresponde àquele adjacente à pluma de contaminação cujo uso da água subterrânea é restringido, a fim de que não haja o espalhamento da pluma por bombeamento de um poço localizado nos arredores.

A ideia de proteção do usuário deste volume de aquífero já vem sendo utilizada como ação de gerenciamento no Estado de São Paulo: o artigo $3^{\circ}$ da Resolução Conjunta SMA/SERHS/SES no 3 (São Paulo, 2006) indica o Estado pode conceder ou não a outorga de um novo poço, caso este se situe numa distância de até $500 \mathrm{~m}$ de uma área contaminada conhecida.

Com base no apresentado nas figuras 2 e 3, uma distância das bordas da pluma ao poço em bombeamento deve ser definida para garantir que a água permaneça potável em longo prazo e evitar o espalhamento da pluma de contaminação no aquífero em direção ao poço.

Os limites de segurança são função de uma série de variáveis, dentre elas a vazão do poço, a porosidade, espessura saturada e a condutividade hidráulica do aquífero, a sua potenciometria, se os poços são totalmente penetrantes ou não, se há interferências hidráulicas entre poços, o tipo do contaminante e as suas taxas de degradação e, especialmente, o grau de heterogeneidade do aquífero.

Um cálculo mais exato desta distância é possível pela utilização de modelos numéricos de fluxo e transporte, que requer, entretanto, a obtenção de grande quantidade de dados para descrever os aquíferos heterogêneos, o deslocamento da pluma de contaminação neste meio e as condições de transiência da explotação dos poços de produção.

Existem outros métodos simples para a delimitação de perímetro de proteção de poços, como o raio fixo calculado ou o método de modelos analíticos, que implicam em realização de simplificações nas determinações (FOSTER et al., 2002; IRITANI \& EZAKI, 2010). O método do raio fixo calculado é o que melhor se ajusta ao cálculo do volume de opção. Se fundamenta numa abordagem geométrica em que uma área circular é definida ao redor do poço, cujo raio é estabelecido por uma equação analítica de fluxo volumétrico (USEPA, 1994). No caso específico, para uma pluma de contaminação preexistente, o raio $\mathrm{R}$ será a distância a partir do poço que irá definir o volume de opção e, portanto, a área em que novos poços não deverão ser instalados ao redor da pluma (Figura 2). 
A Equação 11 indica que o raio é calculado a partir de um tempo de trânsito definido, escolhido como limite de critério, em função das taxas diárias de bombeamento, porosidade efetiva e espessura saturada do aquífero.

$$
R=\sqrt{\frac{Q . t}{\pi \cdot b \cdot n_{e}}}
$$

onde:

$\mathrm{R}=$ raio fixo calculado $(\mathrm{L})$;

$Q=$ vazão do poço de produção ( $\left(L^{3} \cdot T^{-1}\right)$;

$\mathrm{t}=$ tempo de trânsito $(\mathrm{T})$;

$\mathrm{b}=$ espessura da zona saturada do aquífero $(\mathrm{L})$;

$\mathrm{n}_{\mathrm{e}}=$ porosidade efetiva $\left(L^{3} \cdot L^{-3}\right)$.

Os pressupostos utilizados para a adoção do método do raio fixo calculado são de que: (1) o aquífero é homogêneo e isotrópico; (2) o poço tem vazão constante; (3) o aquífero não possui gradiente hidráulico; (4) há fluxo horizontal radial ao redor do poço; e (5) o poço é totalmente penetrante no aquífero. Valores de parâmetros hidrogeológicos de aquíferos do Estado de São Paulo são obtidos em Carvalho \& Hirata (2012), Iritani \& Ezaki (2010) e em Conicelli (2014).

Na Equação 11, a variável mais sensível é o tempo de trânsito, que é definido de forma arbitrária em função do grau de persistência do contaminante. Em geral, um tempo de trânsito de 50 dias é utilizado para a definição da zona de proteção microbiológica imediatamente ao redor de poços de produção (FOSTER et al., 2002). Para contaminantes persistentes, móveis e de degradação complexa, como os solventes organoclorados, a proposta é a de utilização de um valor de tempo de trânsito de 10 anos, conforme utilizado em países europeus (FOSTER et al., 2002; CARVALHO \& HIRATA, 2012). Este valor é considerado de segurança, pois haverá tempo para a ocorrência de atenuação natural do contaminante, que faria reduzir as concentrações na pluma de contaminação. Para os hidrocarbonetos leves de petróleo (gasolina, diesel e similares), o tempo de trânsito de 2 anos é indicado (FOSTER et al., 2002), por serem de degradabilidade mais rápida.

\subsection{Valores Unitários da Água Subterrânea}

$\mathrm{Na}$ valoração, os volumes totais são multiplicados pelo valor de custo unitário do metro cúbico de água (Equação 6). Neste trabalho, o valor unitário da água subterrânea é discutido de duas formas: um equivalente aos custos de substituição ou de extração de água subterrânea por poços; e outro equivalente aos custos de realização da gestão dos recursos hídricos subterrâneos em longo prazo.

\subsubsection{Valores Equivalentes aos Custos de Substituição e de Extração de Água Subterrânea}

A água subterrânea pode ter valor correspondente àquele de substituição da água fornecida por uma concessionária pública ou por uma empresa privada (como aquelas que distribuem água por caminhão pipa). Esta situação pode se aplicar especialmente quando um usuário de água subterrânea tem o seu poço interditado devido à contaminação do aquífero e é obrigado a utilizar a água de abastecimento público em sua substituição. Como referência, nos dias atuais, a concessionária SABESP pratica o valor de $\mathrm{R} \$ 20,42$ pelo metro cúbico de água tratada para consumidores industriais e comerciais na RMSP (acima de 50 m³/mês - SABESP, 2019).

A água subterrânea pode também ter o seu valor correspondente aos custos de extração de água por poços tubulares, que correspondem àqueles que os usuários teriam com a construção, operação e manutenção do poço ao longo de 30 anos de sua vida útil. A Tabela 1 exibe os valores do custo do $\mathrm{m}^{3}$ de água subterrânea extraída por poços situados nos aquíferos sedimentar e cristalino da RMSP, com base em dados médios observados de profundidade e de vazão de outorga dos poços (HIRATA et al. 2012). Dentre as variáveis utilizadas para o cálculo do custo, a mais sensível é a vazão de operação do poço. Assim, uma vazão correspondendo à metade da outorgada resultará que o custo do $\mathrm{m}^{3}$ será o dobro do apresentado na Tabela 1. Outra variável sensível refere-se aos custos de operação do poço, representada pela mão de obra que fará o acompanhamento diário do funcionamento do sistema.

\subsubsection{Valores Equivalentes aos Custos de um Projeto de Ges- tão}

Em situações de casos complexos de contaminação da água subterrânea, onde várias áreas fontes próximas podem ocorrer e as porções mais profundas dos aquíferos são impactadas sem que as responsabilidades tenham sido identificadas claramente, o exercício da aplicação das medidas institucionais previstas na Legislação por parte dos responsáveis legais das áreas contaminadas tem efeito limitado. 
Tabela 1 - Variáveis consideradas para o cálculo do custo do metro cúbico de água extraídos de poços tubulares profundos

\begin{tabular}{|c|c|c|}
\hline & Poço Sedimentar & Poço Cristalino \\
\hline Profundidade (m) & 150 & 300 \\
\hline Vazão de outorga $\left(\mathrm{m}^{3} / \mathrm{h}\right)$ & 8 & 8 \\
\hline Vazão de operação (m³/h) & 8 & 8 \\
\hline Custo de construção ( $\mathrm{R} \$$ em 30 anos) & 330.000 & 220.000 \\
\hline Manutenção (R\$ por mês) (1) & 617 & 633 \\
\hline Operação (R\$ por mês) (2) & 5.000 & 5.000 \\
\hline $\begin{array}{l}\text { Instalação e manutenção de estação de tratamento para re- } \\
\text { moção de Fe (R\$/mês) (3) }\end{array}$ & 650 & 650 \\
\hline $\begin{array}{l}\text { Custos com monitoramento de qualidade da água (análises } \\
\text { químicas) }(\mathrm{R} \$ / \mathrm{mês})(4)\end{array}$ & 1500 & 1500 \\
\hline Produtos químicos (R\$/mês) (5) & 528 & 528 \\
\hline Energia elétrica (R \$/mês) (6) & 1628 & 2559 \\
\hline Outorga e cobrança de uso ( $R \$ /$ mês) & 196 & 196 \\
\hline Custo total mensal (R\$/mês) (7) & 12.905 & 13.279 \\
\hline Custo total em 30 anos $(\mathrm{R} \$)$ & 4.746 .697 & 4.780 .612 \\
\hline Vazão de operação (m³ em 30 anos) & 1.728 .000 & 1.728 .000 \\
\hline Custo do $\mathrm{m}^{3}(8)$ & 2,75 & 2,77 \\
\hline
\end{tabular}

(1) Inclui estimativa de custos de subcontratados, peças e bombas submersas (substituídas a cada 5 anos); (2) custos da equipe de operação, controle e inspeção diária do funcionamento do sistema; (3) inclui os custos de equipamento e mão de obra de uma estação de tratamento para remoção de concentrações de $1 \mathrm{mg} / \mathrm{L}$ de Fe (substituídas a cada 5 anos); (4) relacionados com o plano de monitoramento do Anexo XX da Portaria de Consolidação MS 5/2017; (5) hipoclorito de sódio, utilizado para desinfecção; (6) operação de bombas submersas de 7 e 11 HP de potência, regime de 600 horas/mês e custo de energia de R \$0,52/kWh; (7) acrescido de um fator de contingenciamento de 20\%; (8) calculado dividindo-se o custo total em 30 anos pela vazão de operação em 30 anos. Quantidades e valores obtidos pelo CEPAS-USP para a realização desta pesquisa. Todos os valores se referem a outubro/2018.

Exemplos desta situação são as várias áreas industriais que ocupam regiões extensas na RMSP, como aquelas das várzeas dos principais rios da região (Tietê, Pinheiros e Tamanduateí, até a região do $A B C D$ ), e as vizinhas às principais rodovias da região. Em todas elas, a água subterrânea representa um importante insumo gerador do desenvolvimento, embora uma boa parcela destas áreas industriais encontre-se abandonada, ociosa ou subutilizada e apresentando contaminação (brownfields). Em muitos desses casos, a estratégia de gerenciamento individual de áreas contaminadas tem funcionamento limitado, dada a maior probabilidade de não existência de um responsável legal identificável para várias das propriedades (BARBOSA et al., 2017).

Nestas situações de regiões industriais amplas, avalia-se que a participação do Estado tenha que ser mais efetiva, através da organização e realização de projetos de gestão integrada de áreas contaminadas, adequando as atividades a estratégias consonantes à escala do problema ambiental (BERTOLO, 2017). Recursos públicos seriam necessários, desta forma, para: (1) a formação de banco de dados para a gestão de áreas contaminadas, possibilitando a geração de estudos em escalas apropriadas às atividades de planejamento; (2) a realização de investigações da qualidade do solo e água subterrânea em áreas públicas e industriais onde o responsável legal não tenha sido determinado; (3) o monitoramento da qualidade dos aquíferos explotados por poços tubulares, de forma a realizar a proteção à saúde de usuários de poços próximos de áreas contaminadas; e (4) desenvolver e adaptar tecnologias para a investigação e monitoramento de detalhe da hidrogeologia e do transporte de contaminantes nos aquíferos.

O valor unitário do custo da água subterrânea seria, desta forma, obtido a partir da determinação do custo total de um projeto de gestão integrada de longo prazo, e que seria compartilhado entre os responsáveis legais de uma determinada área geográfica afetada pela contaminação. 0 montante a ser compartilhado por cada responsável legal seria proporcional ao volume de água afetado por cada área contaminada identificada, calculado através da metodologia proposta neste trabalho.

\section{CONCLUSÕES}

Este trabalho objetivou desenvolver uma metodologia para o cálculo do valor econômico dos serviços ecossistêmicos prestados pelas águas subterrâneas e pelos aquíferos. A realização da valoração da água subterrânea complementa a lacuna que existe entre a recuperação da qualidade da água subterrânea, executada pelas ações de GAC, e a necessidade da reparação integral do dano a este recurso, exigidas pela Legislação.

A metodologia de valoração adotada implica na realização do cálculo dos volumes de água subterrânea associados com o 
problema ambiental, multiplicado por um valor de custo unitário de sua substituição. 0 cálculo dos volumes demanda que valores de vários parâmetros hidrogeológicos e geoquímicos dos contaminantes sejam determinados. Os valores unitários da água subterrânea podem ser definidos a partir dos custos de sua substituição ou extração por poços, ou mesmo a partir do compartilhamento dos custos de um projeto de interesse coletivo para a gestão de recursos hídricos subterrâneos no contexto de áreas contaminadas.

A metodologia proposta não tem a pretensão de delimitar os volumes de forma exata, assim como também não utiliza um valor econômico exato para a água subterrânea, dado que este mercado não existe. Mas ela se cabe como uma referência técnica de aplicação simples, de forma que possibilita a quantificação relativa dos problemas ambientais, pois casos de contaminação de maiores dimensões tendem a resultar maiores volumes a serem valorados.

O montante calculado pode não ser considerado o definitivo a ser cobrado, mas é apropriado como uma referência inicial para a negociação com o responsável legal pela contaminação. A disposição para pagar pelo responsável, por sua vez, tende a ser maior à medida que se faz clara a forma como os recursos serão aplicados, em especial se estes forem utilizados para a gestão da água subterrânea e melhoria das condições ambientais do próprio local afetado pelas áreas contaminadas.

\section{AGRADECIMENTOS}

Os autores expressam seus agradecimentos ao geólogo Antonio Pinhatti pela contribuição ao cálculo do custo da água por poços tubulares (Tabela 1). E ao Ministério Público do Estado de São Paulo pelo financiamento e suporte a esta pesquisa.

\section{REFERÊNCIAS}

ALY JR, O.; BERTOLO, R.; HIRATA, R.; PUGGA, B.P. Princípios da valoração dos recursos hídricos subterrâneos impactados por atividades contaminantes. In: LUTTI, J.E.I.; LEITE, L.F.T.C.; ROCHA, L.F.; SERRA T.B. (Org.). Temas de direito ambiental. 1.ed. SP: Imprensa Oficial do Estado de São Paulo, p.161-184. 2015.

ANDRADE, D. C. Modelagem e valoração de serviços ecossistêmicos: uma contribuição da economia ecológica. Tese (Doutorado) - Instituto de Economia, UNICAMP, 2010.

BANN, C.; WOOD, S.C. Valuing groundwater: A practical approach for integrating groundwater economic values into decision making - A case study in Namibia, Southern Africa. International Conference on Groundwater Special Edition. Water SA, v. 38, n. 3, p.461-466, 2012.

BARBOSA, M., BERTOLO, R., HIRATA, R. A Method for Environmenta Data Management Applied to Megasites in the State of Sao Paulo, Brazil. Journal of Water Resource and Protection, v. 9, n. 3, p.322-338, 2017.

BERTOLO, R. Bases técnicas para a gestão de áreas contaminadas por solventes organoclorados em aquíferos fraturados. Tese (Doutorado de Livre Docência) - Instituto de Geociências, USP, 2017.

BERTOLO, R.; HIRATA, R.; CONICELLI, B.; SIMONATO, M.; PINHATTI, A.; FERNANDES, A. Água subterrânea para abastecimento público na Região Metropolitana de São Paulo: é possível utilizá-la em larga escala? Revista DAE, 199, p. 6-17, 2015.
BUSCHECK, T.E., ALCANTAR, C.M., Regression Techniques and Analytical Solutions to Demonstrate Intrinsic Bioremediation. In: Proceeding of the Battele International Symposium on In Situ and On-Site, Columbus, OH Batelle Press, p. 109-116, 1995.

CARVALHO, A.M. e HIRATA, R. Avaliação de métodos para a proteção dos poços de abastecimento público do Estado de São Paulo. Geologia USP, Série Científica, v.12, n. 1, p.53-70, 2012.

CEPAS-USP. Estudo hidrogeológico para o diagnóstico da disponibilidade hídrica subterrânea para o abastecimento de água na Região Metropolitana de São Paulo. SABESP: Relatório Técnico (circulação restrita), 2016. 126p.

CETESB - COMPANHIA AMBIENTAL DO ESTADO DE SÃO PAULO. Relatório de Áreas Contaminadas e Reabilitadas no Estado de São Paulo. CETESB. 2018. 12p. Disponível em: https://cetesb.sp.gov.br/areascontaminadas/relacao-de-areas-contaminadas/. Acesso em 23/07/2019.

CNI - CONFEDERAÇÃO NACIONAL DA INDÚSTRIA. Perfil da Indústria nos Estados. Relatório. CNI. Brasília. 2014. 220p.

CONICELLI, B. Gestão das águas subterrâneas na Bacia Hidrográfica do Alto Tietê (SP). Tese (Doutorado) - Instituto de Geociências, USP.. 2014. $163 \mathrm{p}$.

CUNHA, R.C.A. Avaliação de risco em áreas contaminadas por fontes industriais desativadas - estudo de caso. Tese (Doutorado) - Instituto de Geociências, USP, 1997. 165 p.

DALY, G. Nature's services: societal dependence on natural ecosystems. Island Press, Washington, DC, 1997. 392p.

DALY, H., FARLEY, J. Economia Ecológica: princípios e aplicações. Instituto Piaget, Portugal, 2008. 532 p.

DANIELOPOL, D. L.; GIBERT, J.; GRIEBLER, C.; et al. Incorporating ecological perspectives in european groundwater management policy. Environmental Conservation, v.31, n.3, p.185-189, 2004.

DUNFORD, R. W. Estimating groundwater damage from hazardous substance releases. Journal of Water Resources Planning and Management, v.126, n. 6, p.366-373, 2000.

FABHAT-SERVMAR. Mapeamento das áreas potenciais de risco de contaminação das águas subterrâneas na UGRHI 6 e suas regiões de recarga. Relatório síntese. FABHAT, São Paulo. 2012. 38p.

FENICHEL, E.P.; ABBOTT, J.K.; BAYHAM, J. BOONE, W., HAACKER, E.M.K., PFEIFFER, L. Measuring the value of groundwater and other forms of natural capital. PNAS Proceedings of the National Academy of Sciences of the United States of America. v.113, n. 9, p.2382-2387. 2016.

FOSTER, S.; HIRATA, R.; GOMES, D.; D'ELIA, M.; PARIS, M. Groundwater quality protection: a guide for water utilities, municipal authorities and environmental agencies. World Bank Publication, Washington, D.C. 2002. 103 p.

HARDISTY, P.E. e ÖZDEMIROGLU, E. The Economics of Groundwater Remediation and Protection. CRC Press, 2005. $336 \mathrm{p}$.

HIRATA, R.; BERTOLO, R.; CONICELLI, B.P.; MALDANER, C. Hidrogeologia da Bacia Hidrográfica do Alto Tietê. In Negro et al. Twin Cities Solos das Regiões Metropolitanas de São Paulo e Curitiba. ABMS. São Paulo. p.67-82. 2012.

IPT - INSTITUTO DE PESQUISAS TECNOLÓGICAS. A produção imobiliária e a reabilitação de áreas degradas: contratação de serviços, responsabilidades legais e viabilidade de empreendimentos. IPT/SECOVI, São Paulo/SP, 2018. 122p.

IRITANI, M. e EZAKI, S. Roteiro orientativo para delimitação de área de proteção de poço. Cadernos do Projeto Ambiental Estratégico Aquíferos. 1. ed., n.2. Instituto Geológico SMA-SP. São Paulo, 2010. 48 p.

JOB, C.A. Groundwater economics. CRC Press, EUA, 1. ed. 687p. 2010. 
MOTA, R. S. Economia ambiental. RJ: Editora FGV, 2006. 228 p.

MOTA, R. S. Manual para a Valoração Econômica de Recursos Ambientais. RJ: IPEA/PNUD/CNPq, 1997. 242 p.

NRC - US NATIONAL RESEARCH COUNCIL. Valuing ground water: economic concepts and approaches. Committee on Valuing Groundwater Commission on Geosciences, Environment and Resources. Nationa Academy Press, Washington DC, 1997. 202 p.

PAGE, G.W.; RABINOWITZ, H. Groundwater Contamination: Its Effects on Property Values and Cities. Journal of the American Planning Association, v. 59, n. 4, p.473-481, 1993.

REBOUÇAS, A. Águas Subterrâneas. In REBOUÇAS, A., BRAGA, B., TUNDISI, J. G. (org). Águas doces no Brasil: capital ecológico, uso e conservação. 3. ed. São Paulo: Escrituras Editora, p.111-144, 2006.

RINAUDO, J.D.; LOUBIER, S.; GÖERLACH, B.; INTERWIES, E. Economic assessment of groundwater protection. Executive Summary. BRGM/RC-52323-FR. 2003. 30 p.
SABESP. Comunicado 05/19. Valores de tarifas de água para a RMSP Interior e Litoral, com vigência após 11/05/2019. Disponível em: http://site.sabesp.com.br/site/uploads/file/asabesp_doctos/Comunicado\%205-19.pdf. Acesso em 23/07/2019.

SÃO PAULO (SMA, SERHS, SES). (2006). Resolução conjunta SMA/SERHS/SS n. 3, de 21.06.2006. Disponível em: https://cetesb.sp.gov.br/aguas-subterraneas/legislacao/. Acesso em 23/07/2019.

USEPA - U.S. ENVIRONMENTAL PROTECTION AGENCY. Groundwater and wellhead protection Handbook. EPA/625/R-94/001. USEPA, Office of Research and Development, Washington, 1994. 288p.

WALKER, D.R.; HOEHN, J.P. The economic damages of groundwater contaminationin small rural communities: An application to nitrates. NORTH Central Journal of Agricultural Economics, v. 12, n. 1, p.47-56. 1990.

WIEDEMEIER, T.H.; RIFAI, H.S.; NEWELL, C.J.; WILSON, J.T. Natural At tenuation of Fuels and Chlorinated Solvents in the Subsurface. John Wiley \& Sons Inc. New York. 1999. 617p. 